\title{
BIODIVERSITAS MANGROVE DI KABUPATEN MERAUKE PROVINSI PAPUA
}

\author{
Siti Masiyah* \\ Staf Pengajar FAPERTA Univ. Musamus Merauke, Email: Masiyah@yahoo.com
}

\begin{abstract}
ABSTRAK
Kerusakan mangrove di Indonesia secara umum disebabkan adanya koversi lahan mangrove menjadi tambak ikan atau udang. Di kabupaten Merauke kerusakan mangrove terjadi dikarenakan penggalian pasir dan pemanfaatan mangrove sebagai bahan bangunan. Penelitian ini dilakukan untuk mengidentifikasi mangrove serta kondisi mangrove di Kabupaten Merauke provinsi Papua selatan. Penelitian ini sangat penting dan utama dikarenakan selama ini penelitian INP mangrove di Kabupaten Merauke belum Pernah dilakukan. Pengambilan sampling pada penelitian dilakukan pada tiga Distrik antara lain Naukenjerai ( Kampung Nasem) Distrik Merauke (Kampung Payum) dan Distrik Semangga (Kampung Kumbe) dengan metode transek sebanyak 6 transek dengan ukuran $100 \times 100 \mathrm{~m}$. Hasil penelitian dari Identifikasi mangrove di Kabupaten didapatkan didapatkan jumlah jenis mangrove 8 jenis mangrove pada Distrik Naukenjerai antara lain Avicennia alba, A. Eucalyptifolia, Aegialitis annulata, Aegliceras floridum, Brugueira cylindrica, Acanthus ilicifolus, Sonneratia alba dan $R$. mukronata dengan jenis mangrove Avicennia sp lebih dominan, Distrik payum 11 jenis mangrove antara lain Avicennia. Alba, A. Eucalyptifolia, Aegialitis annulata, Aegiceras corniculatum, Aegliceras floridum, Acanthus abractearus, Brugueira cylindrica, Acanthus ilicifolus, R. mukronata, R. stylosa, dan Sonneratia alba dengan jenis Avicennia sp lebih dominan sedangkan Distrik Kumbe didapatkan 13 jenis mangrove antara lain Avicennia. Alba, A. Eucalyptifolia, Aegialitis annulata, Aegliceras floridum, Brugueira cylindrica, Acanthus ilicifolus, B. Gymnorhiza, B. Hainessii, Ceriop decandra, Bruguiera sexangula, R. Mukronata, $R$. Stylosa, dan Sonneratia alba dengan jenis mangrove Rhizophora sp lebih melimpah daripada yang lain.
\end{abstract}

Kata Kunci : Identifikasi, kondisi, mangrove, Kabupaten, Merauke, Provinsi, Papua.

\section{PENDAHULUAN}

Kabupaten Merauke memiliki potensi sumberdaya alam yang sangat luas, baik baik potensi sumberdaya yang dalam proses pemanfaatan maupun potensi untuk pengembangan sumberdaya alam. Potensi sumber daya alam di Kabupaten Merauke sangat tinggi dan beranekaragam, baik potensi SDA Hutan, SDA Sungai, SDA Pantai, dan SDA Laut. Daerah ini terdiri dari perairan laut Arafura sekitar $75.000 \mathrm{~km}^{2}$, perairan umum (sungai dan rawa) sekitar $71.000 \mathrm{~km}^{2}$ dan garis pantai $1.050 \mathrm{~km}^{2}$ yang membentang dari Sungai Torasi diperbatasan Republik Indonesia dan Papua New Guenia, disebelah Timur sampai pada Sungai Syrest (Data Badan Pusat Statistik Kabupaten Merauke, 2011). Merauke yang terletak di ujung selatan Papua memiliki ekosistem mangrove yang sangat luas. Menurut data yang dirilis oleh Pemerintah Kabupaten Merauke Tahun 2009, Kabupaten Merauke memiliki luasan hutan mangrove. 4.672,382 Ha. Ekosistem mangrove sering disebut sebagai hutan payau atau hutan bakau. hutan mangrove adalah tipe hutan yang khas terdapat disepanjang pantai atau muara sungai yang masih dipengaruhi oleh pasang surut air laut (Nontji, 2007). 
Biodiversitas mengrove pada ekosistem sungai di Kabupaten Merauke belum pernah dilakukan. Sedangkan mangrove pada pesisir atau daerah yang berhadapan langsung dengan laut Arafura pernah dilakukan oleh Masiyah siti (2014) yang dilakukan di pesisir Arafura dengan mengambil tiga titik di Payum, Lampu satu dan Karang Indah yang kesemuanya terletak pada Distrik Merauke. Potensi mangrove pada penelitian ini mengidentifikasi serta memberikan gambaran dari masing-masing spesies. Adapun tujuan dari penelitian ini antara lain: ( 1) untuk mengetahui identifikasi mangrove di Kabupaten Merauke dengan mengambil tiga Distri yaiu Distrik Merauke, Distrik Naukenjerai dan Distrik semangga. (2) mengetahui kondisi dari masing-masing tempat atau stasiun pada ekosistem mangrove.

\section{METODE PENELITIAN}

Penelitian dilakukan di Kabupaten Merauke, tepatnya di 3 Distrik yaitu Distrik Merauke, Distrik Semangga dan Distrik Naukenjerai. Untuk Distrik Merauke sampling diambil pada Kampung Payum, Distrik Naukenjerai sampling dilakukan pada Kampung Nasim dan Distrik Semangga pada Kampung Kumbe. Penelitian dilakukan selama bulan Oktober - Desember 2015 bersama dengan Team Musamus dan KKP.

Kegiatan yang dilakukan di Kabupaten Merauke dengan mengambil data primer dan data sekunder. Pengambilan data Primer mencakup Identifikasi mangrove disepanjang pesisir yang terdapat pada 3 distrik.

\section{HASIL DAN PEMBAHASAN}

3.1. Kondisi daerah Penelitian (Kampung Payum)

Kampung Payum merupakan salah satu Kampung yang terletak di Distrik Merauke, Kampung payum yang terletak di pesisir Arafura memiliki Panjang kurang lebih 2,1km. Masyarakat Kampung payum yang sudah majemuk dengan berbagai suku memiliki mata pencaharian sebagai Nelayan (pencari kepiting, ikan maupun udang), pedagang, pegawai, pengangkut pasir dan pengelolahan ikan asin.

Pantai Payum yang terletak kurang lebih $3 \mathrm{~km}$ dari kota merauke memilik potensi hasil penangkapan ikan dan udang yang sangat baik. Ekosistem mangrove yang dekat dengan pemukiman penduduk, menjadikan degradasi yang tinggi dimana aktifitas masyarakat asli yang menempati pesisir sebagai penjual pasir sehingga menuntut kerusakan habitat mangrove. Selain menyebabkan kerusakan habitat juga kerusakan biodiversty mangrove semakain berkurang.

\subsection{Hasil Identifikasi Mangrove}

Hasil penelitian pada stasiun I (Kampung Payum) yang memiliki daerah sangat luas, hasil identifikasi mangrove didapatkan 11 jenis mangrove. Luasan mangrove hasil dari penelitian dengan menggunakan Drone atau pesawat tanpa awak seluas 1,57 ha. (peta Luasan mangrove dapat dilihat pada Gambar 1). Secara ekologi ekosistem mangrove yang terdapat pada Kampung Payum sangat bervariasi, dimana daerah yang dekat sekali dengan perumahan penduduk, terdapat anakan sungai yang besar selain itu berhadapan langsung dengan laut. Kelimpahan mangrove dari beberapa jenis sangat tinggi, artinya zonasi mangrove sangat terlihat jelas. Zonasi Avicennia yang terdepan dan ukuran pohon yang lebih besar dibandingkan dengan jenis yang lain. Dari hasil penelitian di Kampung Payum mangrove memiliki garis lingkar pohon $45,8 \mathrm{~cm}$. Jenis Rhizophora $s p$ dan Aegialitis annulata dalam bentuk anakan yang membentuk kawasan tersendiri. Keberadaan anakan sungai pada stasiun I ini menjadikan jumlah spesies mangrove Rhizophora sedikit lebih besar. Dari hasil penelitian untuk spesies Avicennia sp memiliki jumlah yang paling tinggi, Rhizophora sp, Aegialitis annulata dan Sonneratia sp.

Hasil identifikasi mangrove di Kampung Payum (TAbel 1), terdapat 11 spesies mangrove, 9 genus antara lain genus Avicennia, Aegialitis, Aegiceras, Acanthus, Rhizophora dan Sonneratia. Dari ke 9 genus ini merupakan mangrove sejati. Dari hasil penelitian yang dilakukanKomposisi jenis mangrove yang 
ditemukan di Pulau Liki, Distrik Sarmi Kota

3 Kabupaten Sarmi Jayapura yang dilakukan oleh Rosye, dkk didapatkan 5 spesies antara lain B. sexangula, S. alba, $R$. apiculata, $R$. Mucronata dan $L$. littorea. Sedangkan Penelitian yang dilakukan oleh Yulinda, dkk. Di Gorontalo didapatkan 7 spesies mangrove antara lain Sonneratia alba, Sonneratia caseolaris, Avicennia alba, Rhizophora mucronata, Ceriops tagal, Eksceocaria agallocha, dan Scypiphora hydrophyllacea. Hasil yang didapatkan di Kabupaten merauke tidak jauh berbeda.

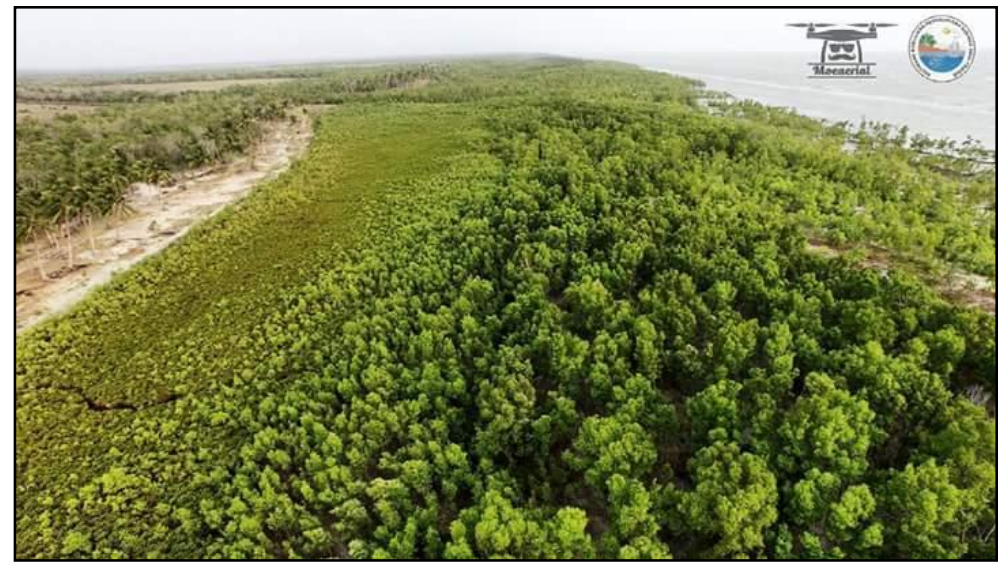

Gambar 1. Luasan mangrove pada pesisir payum Distrik Merauke.

Tabel 1. Hasil Identifikasi mangrove di Kampung Payum

\begin{tabular}{clc}
\hline No & \multicolumn{1}{c}{ Jenis Mangrove } & $\begin{array}{c}\text { Stasiun I (Distrik Merauke) } \\
\text { (Kampung Payum) }\end{array}$ \\
\hline 1 & Avicennia. Alba & $\sqrt{ }$ \\
2 & Avicennia. Eucalyptifolia & $\sqrt{ }$ \\
3 & Aegialitis annulata & $\sqrt{ }$ \\
4 & Aegiceras corniculatum & $\sqrt{ }$ \\
5 & Aegiceras floridum & $\sqrt{ }$ \\
6 & Acanthus abractearus & $\sqrt{ }$ \\
7 & Brugueira cylindrica & $\sqrt{ }$ \\
8 & Acanthus ilicifolus & $\sqrt{ }$ \\
9 & Rhizophora. Mukronata & $\sqrt{ }$ \\
10 & Rhizophora. Stylosa & $\sqrt{ }$ \\
11 & Sonneratia alba & $\sqrt{ }$ \\
\hline & Jumlah Jenis per Statsiun & 11 \\
\hline
\end{tabular}

\subsection{Kondisi Daerah penelitian (Kampung} Nasem)

Kampung Nasem merupakan salah satu kampung yang terletak pada Distrik Noukenjerai. Penduduk Kampung Nasem hampir 90\% merupakan masyarakat asli Papua. Kampung terletak kurang lebih $10 \mathrm{~km}$ dari Marauke Kota. Secara ekologi kampung ini memiliki potensi sumberdaya yang masih sangat alami. Banyak terdapat penduduk Kampung Nasem dari keturunan PNG (Papua
Newgini) sehingga dalam percakapan seharihari banyak menggunakan bahasa Inggris PNG. Masyarakat Kampung nasim sudah sangat maju, aktitifitas masyarakat sebagai petani, Nelayan, pedagang, tukang, Pegawai dll.

Kondisi mangrove yang sangat baik, alami sehingga memiliki potensi sumberdaya perikanan yang tinggi. Hasil tangkapan ikan oleh masyrakat kampung payum sudah 
dijadikan sebagai ikan asin kemudian dikirim dikota untuk dipasarkan.

3.4. Identifikasi mangrove pada Distrik Naukenjerai (Kampung Nasem)

Hasil dari penelitian menggunakan Drone Kampung Nasem memiliki luas hutan mangrove 1,2 ha. Hasil Identifikasi mangrove pada stasiun II Kampung Nasem (Gambar 2) berbeda, pada stasiun II (Kampung Nasem) mangrove yang memiliki luas 1,2 Ha hasil identifikasi didapatkan 8 jenis mangrove (Tabel 2). Dari 8 spesies tersebut banyak di dominasi oleh jenis Avicennia alba, hal ini dikarenakan substrat yang sesuai dengan kelangsungan hidup Avicennia sp selain itu, secara langsung ekosistem mangrove yang ada di Kampung Nasem terletak berhadapan langsung dengan laut. Hasil penelitian didapatkan garis lingkar pohon mangrove terbesar $84,1 \mathrm{~cm}$ selain itu dari survei Avicennia $S p$ yang masih alami terbentuk kawasan tersendiri dimana daerah sampling I terdapat hampir $\mathbf{9 0} \%$ jenis Avicennia sp, terdapat juga Sonneratia, Rhizophora hanya sebagian kecil. Begitu juga dengan daerah sampling II ekosistem mangrove masih banyak didapatkan Avicennia $s p$ dan beberapa jenis Sonneratia, Rhizophora, Aegialitis annulata, Aegiceras floridum yang hanya sebagian kecil. Didapatkan juga jenis Rhizophora pada daerah Sampling II dimana daerah ekosistem mangrove disini terdapat anakan sungai. Secara ekologi mangrove Rhizophora akan tubuh subur dengan baik dengan susbtrat yang liatnya/lumpurnya lebih besar dan salinitas garam yang tidak terlalu tinggi. Hasil keseluruhan pada Kampung Nasem mangrove jenis Avicennia sp, memiliki jumlah yang sangat besar, kemudian Rhizophora sp, dan Sonneratia sp.

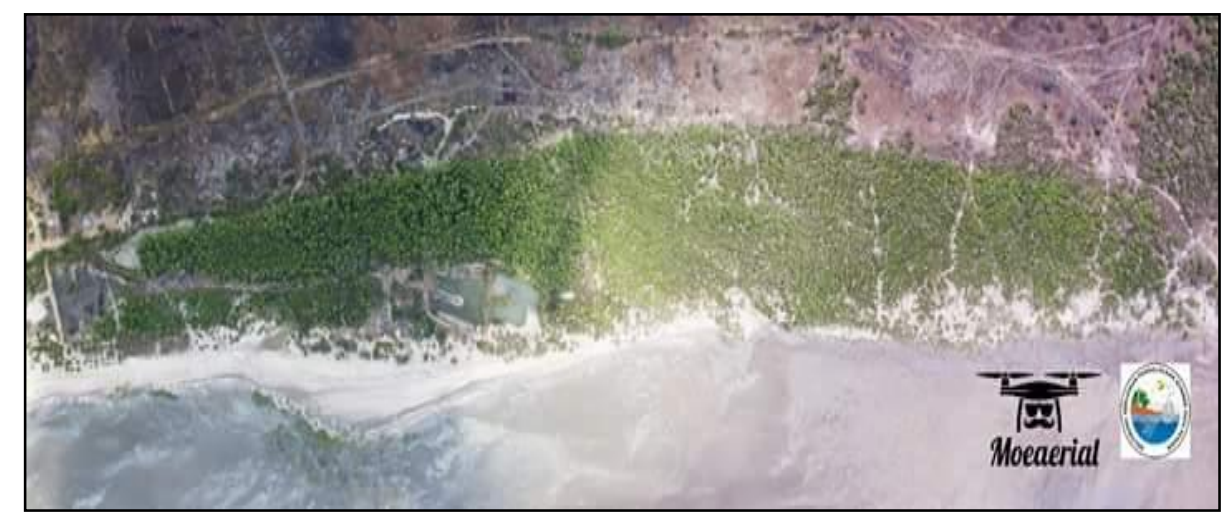

Gambar 2. Luasan Mangrove pada Pesisir Nasim Distrik Noukenjerai

Tabel. 2. Hasil Identifikasi mangrove di Stasiun II Kampung Nasem

\begin{tabular}{clc}
\hline No & \multicolumn{1}{c}{ Jenis Mangrove } & $\begin{array}{c}\text { Stasiun II (Distrik Naukenjerai) } \\
\text { (Nasem) }\end{array}$ \\
\hline 1 & Avicennia. alba & $\sqrt{ }$ \\
2 & Avicennia. eucalyptifolia & $\sqrt{ }$ \\
3 & Aegialitis annulata & $\sqrt{ }$ \\
4 & Aegiceras floridum & $\sqrt{ }$ \\
5 & Brugueira cylindrica & $\sqrt{ }$ \\
6 & Acanthus ilicifolus & $\sqrt{ }$ \\
7 & Rhizophora. mukronata & $\sqrt{ }$ \\
8 & Sonneratia alba & $\sqrt{ }$ \\
\hline \multicolumn{7}{c}{ Jumlah Jenis per Statsiun } & 8 \\
\hline
\end{tabular}

Hasil Identifikasi mangrove pada Kampung Nasem didapatkan 8 spesies mangrove, 6 genus antara lain Avicennia,
Aegialitis, Aegiceras, Brugueira, Acanthus, Rhizophora dan Sonneratia. Hasil identifikasi mangrove di Distrik Naukenjerai Kampung 
Nasem merupakan mangrove sejati. Dari hasil 3 penelitian yang dilakukanKomposisi jenis mangrove yang ditemukan di Pulau Liki, Distrik Sarmi Kota Kabupaten Sarmi Jayapura yang dilakukan oleh Rosye, dkk didapatkan 5 spesies antara lain B. sexangula, S. alba, $R$. apiculata, R. Mucronata dan L. littorea. Sedangkan Penelitian yang dilakukan oleh Yulinda, dkk. Di Gorontalo didapatkan 7 spesies mangrove antara lain Sonneratia alba, Sonneratia caseolaris, Avicennia alba, Rhizophora mucronata, Ceriops tagal, Eksceocaria agallocha, dan Scypiphora hydrophyllacea. Hasil yang didapatkan di Kabupaten merauke tidak jauh berbeda.

\subsection{Kondisi Daerah Penelitian Kampung} Kumbe

Kampung Kumbe secara geografis terletak dimuara sungai kumbe, dan terdapat penyebrangan yang menghubungkan antara kampung kumbe dangan Distrik Kurik. Adanya penyebarangan menjadikan kampung kumbe ramai. Kampung ini dikelilingi oleh perairan baik dari air laut maupun air payau yang berasal dari sumgai kumbe. Penduduk Kampung Kumbe sangat majemuk, begitu juga dengan aktifitas masyarakatnya. Mulai dari nelayan pencari ikan dan Kepiting, petani, pedagang, pengawai dan lain-lain.

Kampung yang di kelilinge dengan ekosistem perairan ini menjadikan potensi mangrove yang tinggi, selain itu keanekaragaman mangrove juga tinggi. Kondisi mangrove yang sangat alami dimana masyarakat jarang melakukan aktifitas penebangan. Mangrove disini merupakan daerah konservasi atau mangrove yang sangat dilindungi oleh masyarakat sekitar. Keberadaan kampung Kumbe sangat tergantung dengan ekosistem mangrove.

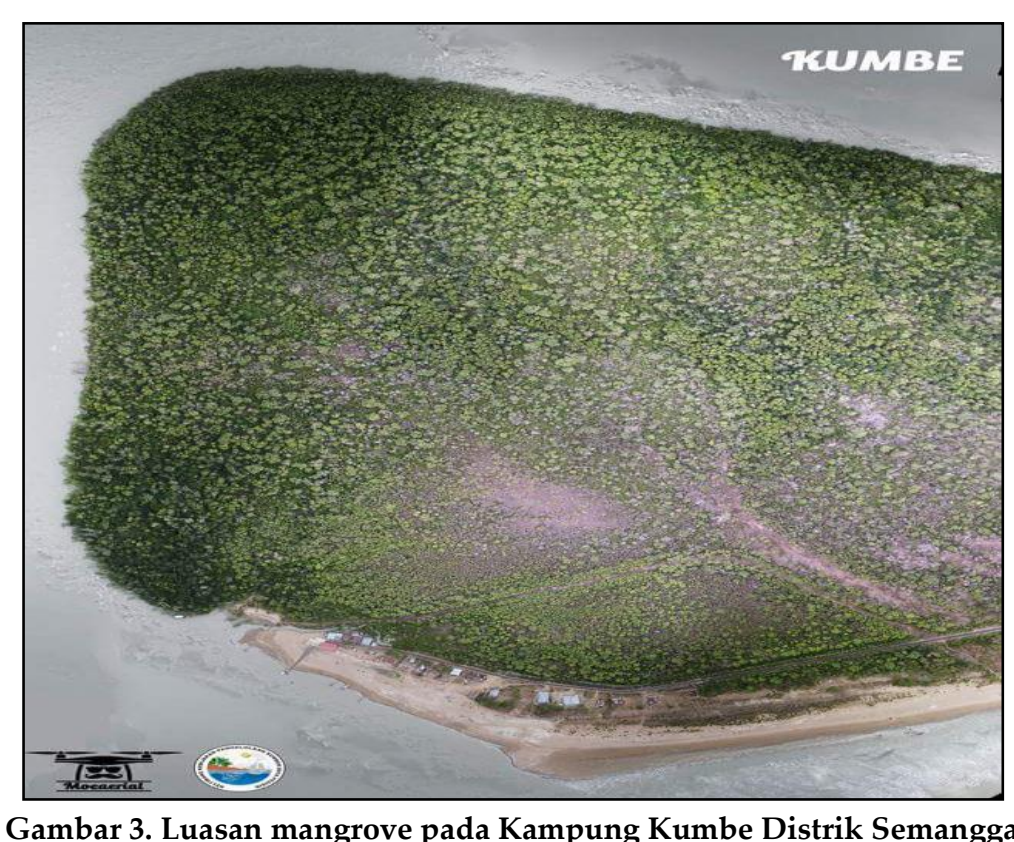

3.6. Identifikasi mangrove Distrik Semangga (Kampung Kumbe)

Hasil penelitian luasan mangrove dengan menggunakan pesawat tanpa awak atau drone 75,25ha dapat dilihat pada Gambar 3. Stasiun III Kampung Kumbe yang memiliki luasan mangrove $75,25 \mathrm{ha}$ kondisi yang sangat menarik, selain mangrove yang masih sangat alami, juga kerusakan mangrove yang sangat kecil sekali dibanding dengan dua stasiun yang lain. Secara ekologi mangrove yang terdapat pada stasiun III ini sebagian besar dikelilingi oleh sungai. Menurut Anonym (2013) Sungai Kumbe yang memiliki lebar $100 \mathrm{~m}$ sangat berpengaruh sekali dengan keanekaragaman dan kelimpahan mangrove. Hasil identifikasi mangrove yang terdapat di Kampung Kumbe didapatkan 13 jenis mangrove dan didominasi oleh jenis Rhizophora $s p$. Mangrove yang sangat alami dan memiliki ukuran lingkar batang terbesar $194 \mathrm{~cm}$ menjadikan mangrove ini mudah untuk dilakukan identikasi, selain 
ini pembentukan Zonasi mangrove sangat jelas. Jenis Rhizophora sp, Bruguiera $s p$ yang mendominansi dipesisir Kumbe. Dilihat dari hasil identifikasi pada stasiun III dibandingkan dengan stasiun yang lain, didapatkan jenis yang paling banyak, hal ini dikarenakan kondisi mangrove yang masih sangat alami atau belum mengalami pengrusakan dan juga memiliki luasan yang tinggi.

Secara keseluruhan sebaran mangrove pada tiga Distrik ditemukan jenis Avicennia sp,
Rhizophora $s p$, Sonneratia sp. Ketiga jenis ini merupakan mangrove sejati, dan dikabupaten merauke sangat berpotensi untuk di kembangkan. Selain itu pada ketiga stasiun juga didapatkan jenis Acanthus ilicifolus, jenis mangrove merupakan indikator adanya kerusakan mangrove, jenis ini paling banyak didapatkan pada stasiun II (payum), Kerusakan mangrove pada stasiun II disebabkan karena adanya penambangan pasir secara terus menerus dan pengambilan mangrove untuk bahan bangunan dalam pembuatan rumah.

Tabel 3. Hasil Identifikasi Mangrove pada stasiun III Kampung kumbe

\begin{tabular}{clc} 
No & \multicolumn{1}{c}{ Jenis Mangrove } & $\begin{array}{c}\text { Stasiun III (Distrik Semangga) } \\
\text { (Kumbe) }\end{array}$ \\
\hline 1 & Avicennia. alba & $\sqrt{ }$ \\
2 & Avicennia. eucalyptifolia & $\sqrt{ }$ \\
3 & Aegialitis annulata & $\sqrt{ }$ \\
4 & Aegiceras floridum & $\sqrt{ }$ \\
5 & Brugueira cylindrica & $\sqrt{ }$ \\
6 & Acanthus ilicifolus & $\sqrt{ }$ \\
7 & Brugueira. gymnorhiza & $\sqrt{ }$ \\
8 & Brugueira. hainessii & $\sqrt{ }$ \\
9 & Ceriop decandra & $\sqrt{ }$ \\
10 & Bruguiera sexangula & $\sqrt{ }$ \\
11 & Rhizophora. mukronata & $\sqrt{ }$ \\
12 & Rhizophora. stylosa & $\sqrt{ }$ \\
13 & Sonneratia alba & $\sqrt{ }$ \\
\hline
\end{tabular}

Hasil Penelitian didapatkan 13 spesies mangrove, 8 genus antara lain Avicennia antara lain Avicennia, Aegialitis, Aegiceras, Brugueira, Acanthus, Rhizophora, Ceriop, dan Sonneratia. Hasil identifikasi mangrove di Distrik Naukenjerai Kampung Nasem merupakan mangrove sejati. Dari hasil penelitian yang dilakukanKomposisi jenis mangrove yang ditemukan di Pulau Liki, Distrik Sarmi Kota Kabupaten Sarmi Jayapura yang dilakukan oleh Rosye, dkk didapatkan 5 spesies antara lain B. sexangula, S. alba, $R$. apiculata, $R$. Mucronata dan $L$. littorea. Sedangkan Penelitian yang dilakukan oleh Yulinda, dkk. Di Gorontalo didapatkan 7 spesies mangrove antara lain Sonneratia alba, Sonneratia caseolaris, Avicennia alba, Rhizophora mucronata, Ceriops tagal, Eksceocaria agallocha, dan Scypiphora hydrophyllacea. Hasil yang didapatkan di Kabupaten merauke tidak jauh berbeda.

\section{KESIMPULAN DAN SARAN}

4.1. Kesimpulan

1. Hasil identifikasi mangrove dari ke 3 stasiun berbeda, ukuran diameter pohon mangrove berbeda.

2. Memiliki luas mangrove tertinggi pada kampung kumbe Distrik semangga.

\subsection{Saran}

Perlu dilakukan penelitian luasan mangrove di seluruh Kabupan merauke, sehingga luasan mangrove di Kabupaten merauke dapat diketahui dengan benar. 


\section{DAFTAR PUSTAKA}

Anonim, 2011. Badan Pusat Statistik, Kabupaten Merauke In Figures. Kabupaten Merauke.

Anonim, 2009. Laporan Tahunan Dinas Kelautan dan Perikanan Kabupaten Merauke

Anonim, 2006. Buku 1 Potret Sumberdaya Kawasan Laut Arafura dan Laut Timor Menuju Pembangunan Berkelanjutan. Forum Pakar Laut Arafura dan Laut Timor.

Bengen, D. G. 2004. Pedoman teknis: Pengenalan dan pengelolaan ekosistem mangrove. PKSPLIPB. Bogor.

Bengen. D. G. dan I. M. Dutton 2004. Interaction: mangroves, fisheries and forestry management in Indonesia. H. 632-653. Dalam Northcote. T. G. dan Hartman (Ed),Worldwide watershed interaction and management. Blackwell science.. Oxford. UK.)

Hartini, S., G. B. Saputro, M. Yulianto, Suprajaka. 2010. Assessing the Used of Remotely Sensed Data for Mapping Mangroves Indonesia. Selected Topics in Power Systems and Remote Sensing. In 6th Wseas International Conference on Remote Sensing (Remote'10), Iwate Prefectural University, Japan. October 4-6, 2010; pp. 210-215

Masiyah siti, 2014. Komposisi jenis dan kerapatan Mangrove di Pesisir Arafura Kabupaten Merauke Provinsi Papua. Jurnal Agrikan Volume 8 Edisi 1, Mei 2015.

Nontji. (2007). Laut Nusantara. Penerbit Djambatan- Jakarta.

Rosye. Dkk. 2015. Analisis Vegetasi Mangrove di Pulau Liki, Distrik Sarmi Kota Kabupaten Sarmi

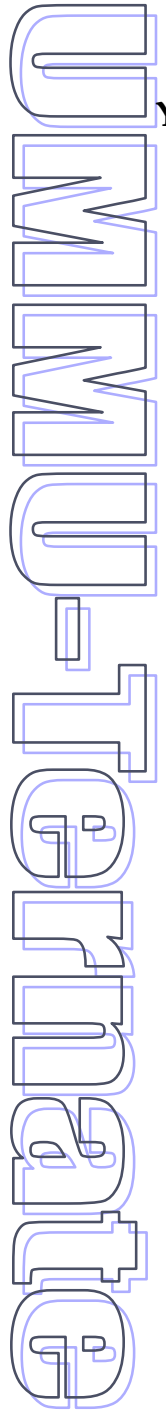
jurnal. Jurnal Ilmiah Perikanan dan Kelautan. Volume 3, Nomor 1, Maret 2015 . Fakultas Perikanan dan Ilmu Kelautan, UNG

Yulinda R. dkk. 2015. Keanekaragaman Jenis dan Indeks Nilai Penting Mangrove di Desa Tabulo Selatan Kecamatan Mananggu Kabupaten Boalemo Provinsi Gorontalo. Jurnal Ilmiah Perikanan dan Kelautan. Volume 3, Nomor 1, Maret 2015 Jurusan Manajemen Sumberdaya Perairan, Fakultas Perikanan dan Ilmu Kelautan, UNG. 